\title{
Reffexões do agir docente sobre o uso das tecnologias nas práticas de leitura e escrita na formação do futuro professor de lingua portuguesa: o desenvolvimento das capacidades de ação profissional
}

Reflections of the teaching agent on the use of technologies in reading and writing practices in the training of the future teacher of portuguese language: the development of the capacities of professional action

Ana Patrícia Sá Martin

Unisinos, UEMA

DOI: https://doi.org/10.5902/2176148534792

\begin{abstract}
Resumo: Investigam-se as reflexões do agir docente que uma professora universitária apresentou sobre o uso das tecnologias nas práticas de leitura e escrita na formação inicial do professor de Língua Portuguesa. Os aportes teórico-metodológicos estão embasados no escopo do Interacionismo Sociodiscursivo, com base em Bulea-Bronckart et al (2013) e Bronckart (2006a); nas concepções de trabalho desenvolvidas pela Clínica da Atividade e Ergonomia e nas características de trabalho de Machado (2009; 2011) e Almeida (2016). Os resultados indicaram alternância entre as figuras de ação, que se constituem como indicadores de que a professora, na posição de actante (e ator, na maioria dos casos), se apropria do discurso sócio profissional que envolve suas práticas pedagógicas no uso das tecnologias, a fim de reconfigurá-lo nas construções do seu trabalho representado.
\end{abstract}

Palavras-chave: Representações do Agir docente. Tecnologias. Professor universitário. Língua Portuguesa.

Abstract: We investigate the reflections of the teaching action that a university professor presented on the use of the technologies in the practices of reading and writing in the initial formation of the teacher of Portuguese Language. The theoretical-methodological contributions are based on the scope of Sociodiscursive Interactionism, based on BuleaBronckart et al (2013) and Bronckart (2006a); in the work conceptions developed by the 
Clinic of Activity and Ergonomics and in the work characteristics of Machado (2009; 2011) e Almeida (2016). The results indicated a change of action figures, which are indicators that the teacher, in the position of actant (and actor, in most cases), appropriates the socio-professional discourse that involves their pedagogical practices in the use of technologies, in order to reconfigure it in the constructions of its represented work.

Keywords: Representations of the Teaching Act. Technologies. College professor. Portuguese language.

Ana Patrícia

Sá Martin

346

\section{Introdução}

As últimas décadas presenciaram uma revolução na área de tecnologia e informação. Com o advento da internet, o acesso à informação tornou-se independente de tempo e espaço. Por consequência, a disseminação de conhecimento pelo mundo inteiro agora é possível e isso afetou não apenas o cenário político e econômico, mas também a área da educação. No Brasil, a Base Nacional Comum Curricular (BNCC) tem como objetivo desenvolver consciência e competência material, social, política e tecnológica que assegurem a prática responsável da cidadania e que apoie estudantes e professores na sua carreira profissional e pesquisas futuras.

O documento enfatiza a importância das Novas Tecnologias como ferramentas para auxiliar o currículo e melhorar a qualidade do ensino. Nesse contexto em que as tecnologias digitais vêm provocando mudanças na maneira de (con)viver no mundo em que atuamos, isso influencia numa mudança de paradigmas em todos os aspectos: econômicos, sociais, ideológicos e educacionais. Assim, expressões como "sociedade do conhecimento" ou "sociedade da informação" se tornaram frequentes nos mais diferentes âmbitos de discussão acadêmica, e a universidade, sobretudo, os cursos de licenciatura, não podem ficar alheios a tal conjuntura.

Aos estabelecimentos de ensino é importante que se observe, reflita e discuta acerca das transformações geradas pela exposição e uso de tecnologias digitais por parte dos docentes e discentes, no intuito de propor estratégias de ensino aprendizagem que proporcionem formas mais efetivas de garantir a autonomia e responsividade nas práticas sociais, haja vista que isolar a universidade da influência que o ambiente digital vem ocasionando na aquisição do conhecimento é também desconsiderá-la como um essencial vetor na promoção do saber. 
Quanto ao ensino superior, especificamente no curso de Letras, o Parecer CNE/CES 492/2001, do Ministério da Educação (MEC), propõe a inserção das tecnologias de informação e comunicação nos projetos pedagógicos: “[...] o curso de Letras deve contribuir para o desenvolvimento das competências e habilidades [...] com a utilização dos recursos da informática [...]" (BRASIL, 2001, p. 30). Diante disso, o MEC prescreve às universidades públicas e / ou particulares o papel de propiciar acesso aos conhecimentos tecnológicos aos seus graduandos em Língua Estrangeira ou Língua Materna.

Nas diretrizes curriculares do MEC, em relação ao curso de Letras, a universidade é vista também "como instância voltada para atender às necessidades educativas e tecnológicas da sociedade [...]" (BRASIL, 2001, p.23). Assim, novas habilidades poderão ser construídas para

Reflexões do agir docente sobre o uso das tecnologias nas práticas de leitura e escrita na formação do futuro professor de língua portuguesa lidar com as diferentes realidades profissionais, incluindo a utilização das tecnologias. O parecer do MEC torna o conhecimento acerca dos aparatos tecnológicos numa exigência para os currículos de Letras.

Abreu-Tardelli (2004) argumenta que, em virtude dessas novas habilidades, o docente universitário pode sentir a necessidade de aprender e/ou atualizar os conhecimentos na área computacional. Em relação aos pareceres e diretrizes do MEC, Abreu-Tardelli (2004), ao analisar o Decreto 2.494/1998, reafirma que há uma representação de que a tecnologia em si resolveria o problema da educação e propiciaria a diminuição de fronteiras entre a docência e a tecnologia. Segundo ela, o professor aparece apenas como aquele que executa tarefas, não havendo diferença se ele é um tutor ou um educador. A tecnologia, desse modo, é representada como suprema e como o fator que conduz o ensino.

As mudanças na forma e na configuração multimodal dos textos na atualidade implicam numa transformação, sem possibilidade de retrocesso, nas formas de ler e escrever. Dionísio (2005), por exemplo, defende a necessidade de revisão do conceito de leitura e de estratégias utilizadas nas aulas, uma vez que, se os gêneros se materializam em formas de representação multimodal (linguagem alfabética, disposição gráfica na página ou na tela, cores, figuras geométricas etc.) que se integram na construção do sentido, os conceitos de letramento e de leitura também precisam ir além do meramente alfabético.

O ensino de Língua Portuguesa e a formação inicial do professor, nesse cenário, não poderiam deixar de ser influenciados; as metodologias de trabalho não poderiam deixar de ser repensadas; e a inclusão 
Ana Patrícia

Sá Martin

dos recursos tecnológicos da informação e comunicação, bem como o desenvolvimento de habilidades condizentes com a utilização eficiente de tais recursos no processo de ensino/aprendizagem de leitura e escrita, consequentemente, não poderia deixar de ser discutido e viabilizado.

O docente envolvido com a língua materna está permanentemente diante do desafio de criação e adaptação de dispositivos de ensino. Assim, a profissionalização de um docente supõe a superação da simples colocação em prática dos materiais e técnicas didáticas disponíveis, passando para outro patamar, que implica desenvolver capacidades de adaptação e criação de novos dispositivos didáticos. Esse, em nosso entender, deve ser o foco de uma proposta de educação para formação de futuros professores.

Nesse sentido, que investigamos as representações do agir docente sobre o uso das tecnologias nas práticas de leitura e escrita na formação do futuro professor de língua portuguesa, e tomamos as contribuições do Interacionismo sociodiscursivo (ISD) como base teórica para nossa pesquisa, levando em consideração também as contribuições dos novos estudos de letramento para a problematização do ensino aprendizagem de línguas, a partir das práticas sociais letradas na contemporaneidade.

A conexão do ISD com o estudo da linguagem se dá a partir do entendimento das práticas de linguagem como formas de ação, por meio das condutas verbais. Desse modo, as práticas linguageiras, através dos textos, constituem os principais instrumentos do desenvolvimento humano. Conforme afirma Bronckart (2003, p.13 apud DREY, 2011), “o quadro interacionista social leva a analisar as condutas humanas como ações significantes, ou como ações situadas, cujas propriedades estruturais e funcionais são, antes de tudo, um produto da socialização".

Nosso trabalho pretende (co) construir saberes relacionados ao campo da formação inicial de professores de língua portuguesa, mais especificamente, sobre a complexa relação entre teoria e prática no desenvolvimento das atividades do ensino. Desta forma, buscamos entender o processo de construção da representação do agir docente universitário quanto ao uso das tecnologias, pois como afirma Dolz (2009 apud CARNIN, 2015):

[Que] a formação profissional de nível universitário rompa com um paradigma aplicacionista. Em lugar de propor um modelo praxeológico a seguir, trata-se de estabelecer uma relação dia- 
lética entre os aportes teóricos, os resultados das investigações científicas e a análise das práticas para, desse modo, poder estabelecer as vantagens e os inconvenientes das diferentes formas da intervenção do professorado.

Dessa maneira, nosso objetivo foi investigar as representações do trabalho docente, através de entrevistas semiestruturadas realizadas por uma bolsista de iniciação científica (PIBIC UEMA/2016) com uma professora de uma universidade na região Sul do Maranhão, a partir de alguns questionamentos:

i) Quais são as finalidades contemporâneas da leitura e da escrita no mundo atual, diante da crescente influência das tecnologias digitais?

Reflexões do agir docente sobre o uso das tecnologias nas práticas de leitura e escrita na formação do futuro professor de língua portuguesa

ii) Como as práticas mobilizadas e as atividades realizadas nos cursos de licenciatura, enquanto lócus de formação de futuros professores podem dialogar com os ambientes digitais?

iii) Como incentivar os futuros professores de língua portuguesa à construção de estratégias de ensino aprendizagem da produção escrita, a partir dos gêneros digitais?

Acreditamos que essas questões oportunizam na identificação de aspectos que interfiram no agir do professor e, a partir dessa análise, se chegar às representações do trabalho docente. Para fazê-lo, utilizamos o escopo do ISD, com base nos procedimentos propostos por Bulea-Bronckart et al (2013), Almeida (2015; 2016) e Machado e Bronckart (2009; 2011).

O trabalho está organizado do seguinte modo: após esta introdução, fazemos uma breve explanação acerca dos Novos Estudos de Letramento, discutindo o uso das tecnologias nas práticas de leitura e escrita na formação do futuro professor de língua portuguesa; em seguida, buscamos conceituar as representações no âmbito da Linguística Aplicada, especificamente na perspectiva do ISD, apresentando a metodologia de análise que orienta este estudo, assim como o procedimento de exame de Interpretação do Agir (BULEA, 2010; 2013), para então seguir com as reflexões sobre alguns resultados obtidos a partir dos dados gerados. Assim, propomo-nos a refletir sobre as representações do agir docente sobre uso que o professor universitário de LP faz das tecnologias para, por fim, apresentar algumas considerações que encerram nosso trabalho. 


\section{Os Novos Estudos do Letramento nas práticas sociais de leitura e escrita}

Quando falamos em letramento, não podemos deixar de mencionar as contribuições de Street (2012; 2014) e Barton (2000), os quais advertem para um letramento que esteja voltado às práticas sociais, não se limitando apenas à esfera escolar. Barton (2000) ressalta a necessidade de se problematizar as ações com a linguagem escrita de forma situada, sendo que cada evento de letramento estará ancorado numa prática social de letramento que vai além dos limites imediatos e está inscrita numa

Ana Patrícia

Sá Martin

350 materialidade social e histórica.

Os estudos acerca do letramento ressaltam uma heterogeneidade de práticas situadas de uso da língua sem que haja estigma às que não correspondem ao domínio escolar. Os eventos de letramento são, em geral, atividades que envolvem textos escritos, seja para serem lidos ou para se falar sobre eles; podemos dizer que são eventos comunicativos mediados por textos escritos.

As práticas de letramento, por sua vez, são os modos culturais gerais em que as pessoas utilizam as práticas da leitura, da escrita e da linguagem em um evento de letramento; são modelos/padrões que construímos a partir dos usos culturais da leitura e da escrita. Entendemos, assim, que os eventos e as práticas de letramento acontecem em variados contextos sociais - incluindo a escola e as diversas agências de letramento (KLEIMAN, 2014) - e possibilitam diferentes letramentos aos sujeitos neles envolvidos, ao mesmo tempo em que os próprios sujeitos interferem em novos eventos e práticas de letramento.

Estudos e experiências acadêmicas como as desenvolvidas por Oakley (2013), Gorospe (2015) e Pegrum et al (2016) demonstram que são múltiplas as possibilidades de utilizar as tecnologias digitais a favor da educação, de maneira mais eficaz e eficiente, de modo que o aluno e professor tenham a oportunidade de aprender e (co)construir o saber de forma mediada e interativa.

Nossa premissa vai ao encontro da realidade no avanço que a tecnologia nos coloca, sejamos docentes ou não, ao defrontar-nos com a variedade de gêneros textuais que estão relacionados ao uso das tecnologias e que circulam na esfera digital. Numa perspectiva acadêmica, esses gêneros têm suscitado discussões importantes, visando a um ensino, sobretudo de língua materna, que adote uma pedagogia dos multiletra- 
mentos, levando o estudo dos vários tipos de textos e gêneros textuais a uma abordagem mais significativa e crítica para a realidade do alunado, como se observa nas pesquisas de Cristóvão (2010), Coscarelli (2016) e Kersch (2016).

A partir desse aporte teórico, notamos que, utilizando alguns gêneros textuais que circulam no ambiente digital, muitos mecanismos podem ser explorados na sala de aula. O professor, todavia, ainda deixa de usá-los por diferentes razões: falta de acesso, falta de formação adequada ou mesmo medo de incorporar essas ferramentas ao ensino. Outro ponto que destacamos é que, com o avanço e popularização da internet e das tecnologias relacionadas ao texto, é necessário desenvolver didáticas que oportunizem usar em sala de aula os gêneros do ambiente digital como ferramenta de aprendizagem no ensino da língua materna, isto é, adotar esses gêneros como mais um material didático para auxiliar na formação de futuros professores no processo ensino-aprendizagem.

\section{Interacionismo Sociodiscursivo (ISD) e a reflexão sobre o agir docente quanto ao uso das tecnologias}

No domínio epistemológico da Linguística, Bronckart (2006b) considera o conceito de representação dentro do ISD ancorada numa visão de desenvolvimento humano baseada nos preceitos de Spinoza, Marx e Vygotsky, além das concepções filosóficas de Saussure, Volochinov e Bakhtin, esse especificamente no âmbito da linguagem.

Percebemos que o ISD está, pois, calcado em vários campos do conhecimento e, por isso, não se coloca apenas nos liames dos estudos linguísticos, dos sociológicos, dos filosóficos ou dos psicológicos, mas sim em uma posição que se caracteriza como uma corrente da ciência do humano, segundo Bronckart (2013). Sobre essa questão, o autor esclarece que

\footnotetext{
o que chamamos de interacionismo sociodiscursivo (ISD) é, inicialmente, uma posição epistemológica e uma tomada de posição sobre o desenvolvimento humano, sobre uma ciência do humano e sobre as condições de seu desenvolvimento. É uma posição que é, ao mesmo tempo, sócio-histórica, materialista-dialética e que considera importantes - eu diria que considera centrais - as questões da linguagem e da formação e educação (BRONCKART, 2013, p.273).
} 
Ana Patrícia

Sá Martin
Assim, quanto às representações, o teórico as define como conhecimentos coletivamente construídos por meio de negociações em interações sociais, manifestadas na emergência do agir comunicativo, “[...] constitutiva do social propriamente dito" (BRONCKART, 2013, p. 33). A atividade humana é caracterizada pelo agir comunicativo, essencialmente social e delimitador das ações humanas. Nesse sentido, as representações são consideradas como conhecimentos coletivos acumulados e cada indivíduo as veicula a partir de três configurações que ele chama mundos representados.

Nessa perspectiva, o estudo das representações do agir docente no viés do ISD concebe os indivíduos como sujeitos posicionados sócio-historicamente (BRONCKART, 2006b), imersos em uma coletividade com a finalidade de interação.

O ISD propõe demonstrar que a linguagem é situada e os textos/ discursos são os instrumentos principais do desenvolvimento humano, tanto em relação aos conhecimentos quanto em relação às capacidades do agir e da identidade dos indivíduos, assumindo, portanto, que a linguagem tem um papel central e decisivo no desenvolvimento humano, em relação aos conhecimentos sobre o agir e a própria linguagem em relação à identidade de cada indivíduo.

Tendo em vista nosso objetivo em analisar as representações do agir docente de professores universitários quanto ao uso das tecnologias nas suas práticas de ensino na formação inicial de professores de língua materna, sob o viés do ISD, descrevemos a metodologia adotada neste estudo.

Uma vez que levamos em consideração as representações de sujeitos envolvidos no âmbito escolar, a metodologia empreendida no presente estudo se classifica como qualitativo-interpretativista. 0 instrumento utilizado para a geração de dados foi entrevista semiestruturada, registrada em gravador de áudio e posteriormente transcrita. Como participantes de pesquisa, escolhemos uma docente de Língua Portuguesa do Ensino Superior, do curso de Letras, numa universidade da região Sul do Maranhão, nominada como D1.

Nossas análises foram embasadas nos aportes teórico-metodológicos do ISD com base nos procedimentos propostos por Bulea-Bronckart et al (2013), Almeida (2016) e Machado e Bronckart (2009; 2011), tendo em vista que essa abordagem considera a linguagem como elemento central, essencial e decisivo para o desenvolvimento humano; além de permitir identificar, nos textos, as representações construídas pelos participantes 
dessa investigação; e, em terceiro, ao fato de que as ações humanas são consideradas em suas dimensões sociais e discursivas.

Abaixo, apresentamos o roteiro de perguntas da entrevista, como Reflexões do agir docente também fazemos uma breve caracterização dos perfis dos participantes da pesquisa, por entendermos que seja relevante ao leitor compreender de onde, como e o porquê das representações do agir docente da professora, ao falar sobre a relação do uso das tecnologias em seu trabalho.

\section{Roteiro para as entrevistas semiestruturadas}

- Qual o ano ou a década em que concluiu sua graduação?

- Quantos anos você tem como docente no ensino superior?

- Quais disciplinas você costuma lecionar no curso de Letras?

- O que significa ser letrado na atualidade?

sobre o uso das tecnologias nas práticas de leitura e escrita na formação do futuro professor de língua portuguesa

- Quais são as finalidades contemporâneas da leitura e da escrita no mundo atual, diante da crescente influência das Tecnologias digitais?

- É importante se dialogar os ambientes digitais com o ambiente pedagógico? Por quê?

- Você já desenvolveu/propôs alguma atividade no ensino superior em que relacionasse o ambiente digital e os conteúdos ministrados em suas disciplinas? Cite e comente algum exemplo.

- Qual (is) o(s) obstáculo(s) para o diálogo entre a didatização do ambiente digital e a formação acadêmica, em sua opinião?

\section{QUADRO 1 - DADOS DOS INTERLOCUTORES DA ENTREVISTA}

\begin{tabular}{|c|c|}
\hline ENTREVISTADORA: BOLSISTA PIBIC & DOCENTE ENTREVISTADA \\
\hline $\begin{array}{l}\text { Iniciou a graduação em } 2015 \text { e, atual- } \\
\text { mente, é bolsista de iniciação científica, } \\
\text { cursando o } 7^{\circ} \text { período de Letras. }\end{array}$ & $\begin{array}{l}\text { Licenciada em Pedagogia (2001) e em } \\
\text { Letras (2009). Começou lecionar no ensino } \\
\text { superior em 2003. Geralmente leciona as } \\
\text { disciplinas de Didática e Estágios supervi- } \\
\text { sionados (tanto de língua materna como } \\
\text { de língua inglesa), com carga trabalho de } \\
40 \text { horas semanais, e também é professora } \\
\text { concursada no Ensino médio estadual. }\end{array}$ \\
\hline
\end{tabular}

Fonte: Elaborado pela autora.

Para a análise dos dados, foi escolhida a metodologia Interpretação do Agir, específica para análise do agir no trabalho, criada pelo grupo LAF, de Bulea-Bronckart (2013) e ancorada no quadro teórico do Interacionismo Sociodiscursivo - ISD (BRONCKART, 2006a, 2006b). 
Essa metodologia de pesquisa busca compreender a realidade das situações de trabalho, investigando e analisando representações, especialmente dos indivíduos em relação ao trabalho real e ao trabalho prescrito, sob a forma de investigação de características essenciais da linguagem, fundamentais para compreender o papel que essa desempenha nas representações, visando à análise da influência que "[...] exerce eventualmente a dimensão linguística dos tipos de discurso nas modalidades de elaboração dessas representações" (BULEA-BRONCKART; LEURQUIN; CARNEIRO, 2010, p. 16), que podem ser percebidas, na análise dos textos,

Ana Patrícia

Sá Martin por meio de marcas linguísticas que o produtor textual lança mão para elaborar sua enunciação. Nesse sentido, acreditamos ser pertinente explicar o significado de conceitos-chave para a análise empreendida.

O termo agir ou agir-referente se refere ao dado e designa a forma de intervenção orientada por um ou vários indivíduos (actantes) nas suas relações de trabalho. Conforme define Bulea-Bronckart (2013), actante é um termo neutro que se refere a qualquer pessoa que possa se implicar no agir. A partir do momento em que o actante se implica em um agir específico, com motivos, capacidades e intenções para realizar determinada ação, ele se transforma em ator. Caso ocorra o contrário, quando não lhe forem atribuídas essas propriedades, o termo agente é conferido ao actante no discurso. Isto é, os agentes não possuem propriedades e podem ser os próprios actantes no discurso ou qualquer indivíduo que interaja com o actante em algum contexto da enunciação.

Essa análise do agir busca compreender o que Bulea (2013) define como trabalho representado dos docentes, isto é, as interpretações do trabalho dos professores, como eles entendem as suas atividades, do que seja promover práticas de linguagem com o uso das tecnologias na formação inicial, como conhecem e teorizam sobre como foi e como deveria ser esse uso na prática de ensino aprendizagem. Assim, o agir de cada actante pode se constituir de um trabalho, cuja estrutura pode ser formada por documentos institucionais, tarefas ou descrições dos próprios actantes, como no caso das entrevistas, as quais se caracterizam por mobilizar vários tipos de discursos e sequências, independentes da temática evocada durante o processo de entrevista.

É nessa perspectiva que a Interpretação do Agir se vê ancorada ao ISD, pois primeiramente ela procura abordar as condições de produção do gênero de texto no qual os discursos das representações foram produzidos, segundo as proposições bakhtinianas e, posteriormente, faz 
[...] uma abordagem da arquitetura interna dos textos que atribui uma importância determinante aos tipos de discurso, como configurações de unidades linguísticas interdependentes, comprovando um determinado modo de relação, de uma parte com o conteúdo referencial, de outra parte com a situação de comunicação, cujo texto é o produto. (BRONCKART; LEURQUIN; CARNEIRO, 2013, p. 15).

A análise dos dados acontece por meio da identificação e interpretação dos elementos ou expressões mais significativas que denotam opiniões a respeito do tema exposto através da dinâmica da entrevista. Dessa forma, depois de transcritas, as falas da entrevista foram agrupadas e classificadas de acordo com conteúdos temáticos ou princípios temáReflexões do agir docente sobre o uso das tecnologias nas práticas de leitura e escrita na formação do futuro professor de língua portuguesa ticos elaborados pelo entrevistador, como dispõem Bronckart (2006c) e Bulea (2013), ou seja, foram agrupadas pelos temas mais relevantes na entrevista.

A partir da divisão em conteúdos temáticos, as falas forma divididas em segmentos formados por duas categorias: os Segmentos de Orientação Temática (SOT), de introdução de um determinado tema elaborado pelo entrevistador, classificados após o agrupamento dos temas expostos nas entrevistas e Segmentos de Tratamento Temáticos (STT), produzidos pelo entrevistado em resposta a uma questão proposta pelo entrevistador. Em suma, é uma resposta, um corte realizado por meio dos assuntos que emergiram nas entrevistas, com a finalidade de organizar a análise das opiniões dos actantes.

Delineadas as definições sobre as duas categorias de segmentos temáticos, a análise da entrevista partiu de recortes específicos de acordo com temas diversos. Após o recorte dos temas, os STTs passaram por uma categorização, o que Bulea $(2010 ; 2013)$ denomina como figuras de ação, termo que designa as configurações interpretativas transversais e recorrentes do agir, oriundas a partir da análise do conjunto dos segmentos temáticos que focalizam o agir das actantes.

As figuras de ação visam a analisar a influência que o agir exerce eventualmente na dimensão linguística dos tipos de discurso, nas modalidades de elaboração das representações que cada actante tem do seu trabalho. Desse modo, são elencadas cinco figuras de ação propostas por Bulea (2013): ação ocorrência, ação acontecimento passado, ação experiência, ação canônica e ação definição. Dessa forma, a partir dos recor- 
Ana Patrícia

Sá Martin

tes das entrevistas em segmentos de orientação temática (SOT) e segmentos de tratamento temático (STT), algumas figuras de ação foram identificadas, de acordo com as semelhanças discursivas elencadas na pesquisa desenvolvida pelo LAF.

A interpretação do agir das actantes também mobiliza um conjunto de procedimentos de análise textual. A abordagem textual discursiva (BULEA, 2013) contempla a análise com base em três elementos: as características gerais dos textos (aspectos da infraestrutura textual dos discursos dos actantes que constituem as planificações e organização temporal, por exemplo), as dimensões do agir (dimensões do agir consideradas ou tematizadas nos textos produzidos, tais como a sua estrutura e informações externas das entrevistas, além dos resultados esperados e/ou obtidos com o agir e das hipóteses sobre a situação de produção de linguagem em relação ao agir) e os meios linguísticos utilizados na formação textual do agir (estruturas linguísticas mobilizadas para exprimir as dimensões do agir, tais como os mecanismos de textualização com suas propriedades nominais e verbais, assim como os mecanismos enunciativos presentes nas unidades de modalização que indicam o posicionamento do actante no seu discurso).

Assim como relatado por Bulea, Leurquin e Carneiro (2013, p. 116-117), quando referem-se às entrevistas do ciclo de tutorado analisado, no caso do agir do professor,

[...] notamos que a interpretação linguageira desse profissional reproduz, no plano discursivo, a sua dupla função de "dar aula" (implicação própria no agir) e de fazer com que os alunos realizem algo (implicação dos outros no agir). Sendo assim, vemos repetir aqui o jogo dinâmico entre a dimensão praxiológica e a dimensão linguageira do funcionamento humano, ambas inseparáveis e mutuamente determinantes.

Tal observação foi destacada pelas autoras como uma característica particular do discurso do professor, e, por isso, também as figuras de ação externa serão aqui levadas em consideração em nossas análises, concomitantemente às figuras de ação interna. Conforme assinalado pelas pesquisadoras (2013, p. 116-117), “as figuras de ação externa, nas quais o professor reflete, interpreta e elabora linguageiramente o agir dos outros protagonistas (aluno, alunos, outros professores)". 
[...] Nestas figuras, a reflexão sempre é feita pelo profissional, que ainda é a fonte das representações textualizadas, mas estas representações dizem respeito às porções ou às dimensões do agir assumido por outros protagonistas e não por ele mesmo. Chamamos atenção para o fato de que não se trata de um outro qualquer, mas de coactantes, isto é, de alguém implicado no agir-referente, seja pela presença física-temporal, seja pela função social que ocupa. [...] no seio de um mesmo segmento temático, a figuração do agir do próprio professor é imediatamente seguida da figuração do agir dos alunos, parecendo quase indissociáveis desta.

(BULEA; LEURQUIN; CARNEIRO, 2013, p. 116-117, 125).

Buscando investigar as reflexões do agir docente que a professora participante ${ }^{1}$ tem em relação às tecnologias na formação inicial de professores, foram selecionados dois temas para interpretação do agir, elencados segundo a sua importância e a ordem de aparição na entrevista, a partir de questionamentos específicos que fizemos acerca da importância do diálogo entre as tecnologias na formação inicial de professores; da experiência com atividades no ensino superior em que relacionasse as tecnologias e os conteúdos ministrados em suas disciplinas; e dos obstáculos para didatização das tecnologias.

Conforme afirma Almeida (2016, p.17), as verbalizações não são meras traduções literais do que dizemos, as figuras de ação permitem identificar aspectos linguísticos e discursivos que são escolhas do falante, as quais são impregnadas de significações e podem ser apreendidas nas representações elaboradas sobre o agir. A autora ressalva ainda que os diferentes pontos de vista acionam diferentes instâncias e categorias de actantes envolvidos no trabalho, mais ator ou mais agente, (continuum de atoridade), demonstrando em que medida o falante se envolve no que diz, o que acaba refletindo o teor dos debates sociais dos quais são parte os participantes. Nesse sentido, para a investigação aqui empreendida, escolhemos as figuras de ação experiência, acontecimento passado e definição.

1 A escolha por essa professora para corpus do presente trabalho deu-se em virtude da recorrente menção, nas entrevistas com os outros docentes não analisados aqui, à Didática como sendo a principal e/ou mais adequada disciplina para proporcionar perspectivas pedagógicas quanto ao ensino com os recursos tecnológicos. 
Ana Patrícia

Sá Martin
3.1 Tema da reflexão do agir docente quanto à importância da didatização das tecnologias na formação inicial de professores

Visando averiguar as representações durante a reflexão do agir docente quanto à importância da didatização das tecnologias, tivemos o seguinte Segmento de Orientação Temática (SOT):

- Segmento de Orientação Temática (SOT): É importante se dialogar os ambientes digitais com o ambiente pedagógico? Por quê?

- Segmentos de Tratamento Temático (STT) D1:

1 "[...] é de fundamental importância que a escola estabeleça

2 essa ponte, essa ligação entre a tecnologia e o ambiente

3 pedagógico porque senão nós vamos ficar fechados em quatro

4 paredes, ensinando numa metodologia tradicional e o nosso

5 aluno vai estar anos-luz a nossa frente, porque ele também

6 tem acesso às novas tecnologias e a escola não pode se furtar

7 -esse debate não pode ficar alheio a esse contexto, então ela

8 pode sim trazer as tecnologias para dentro do espaço

9 pedagógico e pode ver nas tecnologias, ferramentas, suportes

10 que vão auxiliar no processo ensino aprendizagem [...]

11 quando se fala da academia, e nós estamos formando

12 profissionais para o mercado de trabalho, eu não vejo como

13 separar a formação docente do uso das tecnologias digitais.

14 São elementos que são interdependentes, então os futuros

15 professores ao passarem pela academia têm que ter acesso a

16 essas ferramentas têm que se ter uma base sólida a respeito

17 disso e, na escola onde eles forem trabalhar eles poderem

18 fazer essa ponte entre a tecnologia e o espaço pedagógico [...]".

A partir dos trechos selecionados, é possível perceber que há uma coerência entre SOT e STT, uma vez que ambos se correspondem - perguntas e respostas. Assim, em relação à importância da didatização das tecnologias na formação inicial de professores, notamos que foi predominante a figura de ação experiência e os seguintes actantes foram elencados:

- Nós/nosso [(eu) a professora + demais docentes]: linhas 3, 4, 11.

- Aluno: linhas 5, 15, 16.

- Escola [(Ela) - enquanto agência de letramento]: linhas 6, 7, 8.

- Eu: linha 12.

- Futuros professores/ Eles: linhas 14, 15, 17. 
Desse modo, podemos dizer que identificamos a presença da figura de ação interna de experiência no trecho destacado. Do ponto de vista da organização textual, essa figura de ação está inserida num contexto de discurso interativo, marcado pelos turnos de fala da entrevistadora e da professora. A expressão 'anos-luz' funciona como advérbio de caráter generalizante, para enfatizar a discrepância de perspectivas (do aluno e do professor formador) quanto ao uso das tecnologias; tendo seu sentido reforçado pela presença predominante do tempo verbal presente genérico, ao se referir às ações rotineiras do agir do docente $\mathrm{e}$ de suas (possíveis) influências.

Conforme assinalado acima, percebemos a ocorrência de múltiplas formas para indicar a agentividade e, no caso, Nós/nosso [(eu) a professora + demais docentes], Escola [(Ela) - enquanto agência de letramento] e Eu marcam a responsabilidade enunciativa da professora. Assim, é possível demonstrarmos a atoridade da professora em caráter triplo, revelando uma tensão entre o individual e o coletivo, ressaltada por Bronckart (2008).

Observamos que são predominantes os usos da $1^{\mathrm{a}}$ pessoa do plural (Nós/nosso) e a da $3^{\text {a }}$ do singular, representado pelo actante pela instituição Escola, que acaba por remeter a todo um conjunto de sujeitos e/ou fatores que constituem uma escola e seu papel formador, no caso, a principal agência de letramento que pode promover uma formação didática que problematize a didatização das tecnologias no processo de ensino aprendizagem.

Bulea (2010, p. 137) assinala que a figura de ação experiência traz a "cristalização pessoal de múltiplas ocorrências vividas do agir e propõe uma espécie de balanço do estado atual da experiência do actante em relação à tarefa concernente". No caso em questão, a professora aborda acerca da "ponte, essa ligação entre a tecnologia e o ambiente pedagógico", necessária, segundo ela, na formação docente; notamos explicitamente, em todo trecho em análise, quanto a professora recorre ao papel do (agir) do professor nesse processo de didatização das tecnologias digitais.

Outra característica perceptível nesse trecho diz respeito a como a professora expressa seu posicionamento quanto ao uso das tecnologias no agir docente, ao empregar as modalizações deôntica, pragmática e apreciativa, vejamos:

- "é de fundamental importância que [...] senão nós vamos ficar fechados em quatro paredes";

- “[...] a escola não pode se furtar a esse debate, não pode ficar alheia a 
esse contexto então, ela pode sim trazer as tecnologias para dentro do espaço pedagógico e pode ver nas tecnologias, ferramentas, suportes que vão é auxiliar no processo ensino aprendizagem".

Desta forma, identificamos a capacidade de reconfiguração do agir da professora, que precisa, junto com a universidade, empreender mecanismos que auxiliem na didatização das tecnologias digitais na formação inicial de professores.

Ana Patrícia

Sá Martin

360

\subsection{Tema da Representação da Experiência com as tecnologias no} agir docente

Visando averiguar as representações do agir docente quanto à experiência com as tecnologias, tivemos o seguinte segmento de Orientação Temática (SOT):

Segmento de Orientação Temática (SOT): Você já desenvolveu/propôs alguma atividade no ensino superior em que relacionasse o ambiente digital e os conteúdos ministrados em suas disciplinas? Cite e comente algum exemplo.

- Segmentos de Tratamento Temático (STT) D1:

1 “[...] fiz vários usos e um que eu me recordo agora, foi numa

2 turma do Curso de Letras, em que eu ministrei a disciplina

3 Didática e aí nós criamos uma página numa rede social e a

4 terceira atividade avaliativa da disciplina foi voltada pra

5 análise do livro didático, então, os alunos fizeram a análise

6 do livro didático em dupla e postavam na página a

7 apresentação de seu trabalho e os demais colegas tinham por

8 obrigação ler o trabalho e, além de ler, ((gesto com as mãos

9 e bate levemente na mesa)), tinham que opinar a respeito do 10 trabalho dos colegas, então, foi bem interessante porque

11 todos eles se esforçaram pra colocar o seu trabalho na 12 página do grupo e também tinham que baixar os arquivos dos 13 demais colegas e se posicionarem a respeito daquilo que os 14 colegas tinham produzido. [...] ministro a disciplina de 15 Didática... é uma disciplina comum a todos os cursos de 16 formação de professores e ela deve possibilitar ao aluno 17 utilizar os recursos tecnológicos como ferramentas 18 didáticas, então, se o professor de didática não tiver essa 19 visão, a formação do professor acaba que sendo deficitária 20 porque deixa de trabalhar um eixo que é muito importante 
21 dentro da formação que é o uso das tecnologias digitais

22 no processo ensino aprendizagem [...] eu faço sempre questão

23 de frisar isso durante a disciplina de Didática e nos

24 estágios, primeiramente nas microaulas, eu sempre solicito

25 aos alunos que façam preparação de micro aula tendo como

26 recursos, alguns dos recursos das tecnologias digitais,

27 sabendo da deficiência das escolas, da problemática do

28 laboratório de informática, da velocidade da internet, que

29 não é satisfatória nas nossas escolas municipais, mesmo com

30 todos esses obstáculos, é importante que os alunos já no

31 estágio façam o uso dessas ferramentas digitais."

A partir dos trechos analisados, é possível perceber que há uma Reflexões do agir docente sobre o uso das tecnologias nas práticas de leitura e escrita na formação do futuro professor de língua portuguesa

coerência entre SOT e STT, uma vez que ambos se correspondem - perguntas e respostas. Assim, em relação à experiência com a didatização das tecnologias na formação inicial de professores, notamos que foi predominante a figura de ação acontecimento passado e os seguintes actantes foram elencados:

- $\quad$ Eu/Nós: [(eu) a professora + alunos]: linhas 1, 2, 3, 14, 22, 24, 29.

- Alunos/ Eles: linhas 5, 6, 7, 8, 9, 11, 12, 13, 14, 5, 301, 31..

- Didática [disciplina] - enquanto agência de letramento: linhas 15, 16.

Nesse sentido, podemos dizer que identificamos a presença da figura de ação acontecimento passado no trecho destacado. Segundo Almeida (2016, p. 21), a figura de ação acontecimento passado é um relato interativo e trata da narração de fatos relacionados ao agir dos participantes, com caráter ilustrativo acerca de sua experiência ou de sua prática.

Do ponto de vista da organização textual, essa figura de ação utiliza o relato como organização discursiva, tematizando o agir como um evento no passado, como uma unidade praxiológica. Contudo, como ressaltam Bulea, Leurquin \& Carneiro (2013, p. 120-121), uma vez que a agentividade é centrada no actante (profissional) que conta a história, que se insere como elemento, esse relato adquire uma característica de interatividade, sendo, portanto, um relato interativo, extraída do passado inserida num contexto de discurso interativo, marcado pelos turnos de fala da entrevistadora, da professora, e pelas marcas de oralidade aí, então, e a repetição da conjunção $e$, como organizadores sequenciais da fala. 
Identificamos também o uso dos advérbios agora, sempre e já, funcionando como expressões de temporalidade, evocando um eixo de temporal situado antes da realização da entrevista, quando a professora conta sobre sua experiência em relação ao uso das tecnologias na formação inicial de professores.

Para enfatizar a perspectiva de agir relatado, a professora tem sua fala marcada pela presença predominante dos tempos verbais pretéritos perfeito e imperfeito, ao se referir às ações rotineiras do (seu) agir e de (suas) experiências docentes, conforme vemos em fiz, foi, ministrei, cria-

Ana Patrícia

Sá Martin mos, tinham, postavam, etc., os quais funcionam como elementos de retomada das tarefas (experiências) realizadas pela professora e pelos alunos.

Além disso, as formas verbais encontradas no trecho revelam a alternância de posicionamento de planos de diferentes processos, isto é, o primeiro plano refere-se fundamentalmente ao trabalho da professora e às atividades dos alunos, representado pelo pretérito perfeito; e o segundo plano refere-se aos fatos da narrativa, representado pelo pretérito imperfeito.

A agentividade aparece indicada pela $1^{\text {a }}$ pessoa do singular $(\mathrm{eu})$, sinalizada em verbos como fiz, ministrei, marcando a atoridade profissional da professora, sinalizando a capacidade de proposição e desenvolvimento do uso didático das tecnologias, o que também proporciona alto grau de implicação da professora no contexto narrado. Observamos ainda que junto do "eu" da professora, aparecem "alunos (eles)", indicando a atoridade destes.

Outra característica percebida nesse trecho diz respeito a como a professora expressa seu posicionamento quanto à experiência no uso das tecnologias no (seu) agir docente, ao empregar as modalizações deôntica, pragmática e apreciativa:

- “(eles) os demais colegas tinham por obrigação ler o trabalho $e$, além de ler, tinham que opinar a respeito do trabalho dos colegas;"

- " “...] foi bem interessante porque todos eles se esforçaram pra colocar o seu trabalho na página do grupo;"

- "(eles) tinham que baixar os arquivos dos demais colegas e se posicionarem a respeito daquilo que os colegas tinham produzido;"

- “[...] ela, (a Didática), deve possibilitar ao aluno utilizar os recursos tecnológicos como ferramentas didáticas;"

- “[...] é importante que os alunos já no estágio façam o uso dessas ferramentas digitais." 


\subsection{Tema da Representação dos obstáculos/superação para didati-}

zação das tecnologias na formação inicial de professores

Este segmento temático busca investigar as representações que a professora apresentou durante a reflexão do seu agir docente acerca dos obstáculos em usar as tecnologias nas práticas de leitura e escrita na formação do futuro professor de língua portuguesa.

- SOT: Em sua opinião, quais os obstáculos para o diálogo entre a didatização do ambiente digital e a formação acadêmica?

- Segmentos de Tratamento Temático (STT) D1:

1 "Bom, eu penso que um principal obstáculo reside, por

2 exemplo, em termo de universidade numa carga horária muito

3 extensa das disciplinas, esse é um desafio como trabalhar

4 todos esses conteúdos da ementa num prazo muito curto, outra

5 questão nessa problemática é que nem sempre você tem um

6 laboratório de informática disponível para todos os alunos.

7 Quando você tem um laboratório, você tem um número reduzido

8 de equipamento ou você tem uma internet muito lenta que às

9 vezes até desmotiva o professor a levar os alunos para o

10 laboratório, e nas escolas não é muito diferente também,

11 [...]certamente, é fundamental que a universidade, que os

12 cursos de formação de professores se atentem para isso, né?

13 Nós vemos a terceira revolução digital, terceira revolução 14 tecnológica e não podemos ficar fora desse contexto. Então a

15 formação de professores precisa atentar pra isso de elencar

16 uma disciplina específica para trabalhar letramento digital

17 com os futuros professores".

No trecho acima, acreditamos que a figura de ação predominante foi a de ação interna definição, pois, segundo Bulea, Leurquin \& Carneiro (2013, p. 124), essa figura resgata uma compreensão do agir enquanto "fenômeno no mundo", convidando a uma reflexão em termos de redefinição, explicitação do que ele é. Essa figura, diferentemente das demais, não tematiza os actantes, nem a organização do agir, mas contém fatores considerados pertinentes, suscetíveis de circunscrevê-los e de diferenciá-los de outros tipos de agir.

Almeida (2015) argumenta que a figura de ação definição possui menor incidência de contextos propícios à expressão da atorialidade 
Ana Patrícia

Sá Martin

364

porque o posicionamento enunciativo da professora se dilui nas modalizações expressas por construções impessoais ("é fundamental", "é um desafio") ou por "você", "a universidade”, “a formação de professores”. O contexto que confere maior atorialidade na figura de ação definição, como visto no trecho acima, ocorre com a presença do dêitico pronominal "eu" junto ao verbo de responsabilidade enunciativa "penso", indicando capacidades epistemológicas.

Observamos uma reflexão a respeito de escolhas e possibilidades didático-metodológicas das tecnologias para as aulas de Língua Portuguesa na universidade. Vale ressaltar que, no início da fala da professora, a verbo na $1^{\mathrm{a}}$ pessoa do singular demonstra que a figura de ação definição não acontece de forma "pura" e isolada nos dados, mas, ainda que raros, ilustra indícios da figura de ação ocorrência, relevando que essa discussão acontece de maneira contextualizada e procura realizar uma síntese entre as diversas vozes que perpassam a produção linguageira desses professores.

\section{Considerações Finais}

Compreender o processo de desenvolvimento pelo qual passam professores ao refletirem sobre seu agir profissional é um trabalho complexo e permanente. Nele está implicada a busca por desenvolver procedimentos e instrumentos que aproximem espaços tidos como prioritariamente de formação, de atuação e de investigação. Está envolvido, assim, um esforço constante por esclarecer o que é o trabalho docente e suas múltiplas dimensões, sobre os mais diversos contextos dessa atividade.

Nesse sentido, podemos afirmar que a principal contribuição do presente estudo está em oferecer um olhar a respeito do agir docente do professor formador, quanto ao uso das tecnologias digitais na formação inicial do futuro professor de língua materna. Tal reflexão pode funcionar como mecanismo de investigação desse contexto e também de desenvolvimento individual e coletivo. Refletir acerca da representação do trabalho do professor universitário, desse modo, é algo de suma pertinência. Mesmo porque, tal discussão pode nos fornecer subsídios úteis para organizar novos modos de refletir e de agir quando da profissão docente.

Embora a professora entrevistada tenha relatado atividades com o uso das tecnologias, esse fator não se tornou decisivo para a promoção de eventos de letramento digital, segundo os seus discursos, pois 
foi recorrente no seu discurso a necessidade e urgência de uma maior e adequada promoção de eventos de letramento digital nas aulas de língua materna.

Com esse estudo, também constatamos que o uso da tecnologia não vai, por si só, modificar a concepção que cada professora tem sobre o processo de ensino-aprendizagem. Por essa razão, em relação à alternância entre as figuras de ação que se evidenciaram ao longo das abordagens textuais discursivas (ação experiência, acontecimento passado e definição), foi possível concluir que essas se constituíram como indicadores de que a professora, na sua posição de actante (e ator, na maioria dos casos), se apropria e interioriza no discurso sócio-profissional que envolve as suas práticas pedagógicas o uso das tecnologias, a fim de reconfigurá-lo no seu conjunto, tentando, assim, trazer uma ou

Reflexões do agir docente sobre o uso das tecnologias nas práticas de leitura e escrita na formação do futuro professor de língua portuguesa

\section{REFERÊNCIAS}

ABREU-TARDELLI, L. O ensino como trabalho: uma abordagem discursiva. São Paulo: Contexto, 2004.

ALMEIDA, A. P. de. Docência de língua materna: o professor como ator do seu próprio agir. Tese (Doutorado em Linguística Aplicada). Unisinos, São Leopoldo, 2015.

ALMEIDA, A. P. Apreensão e análise do discurso reflexivo do professor. IN: GUIMARÃES, A.M.M.; CARNIN, A.; BICALHO, D.C. (Orgs.). Formação e trabalho docente: múltiplos olhares para o ensino de língua materna. Campinas, SP: Pontes Editores, 2016. P. 13-31.

BARTON, David; HAMILTON, Mary. Literacy practices. In: BARTON, David; HAMILTON, Mary; IVANIC, Roz (Org.). Situated literacies. London: Routledge, 2000, p. 7-15. 
BRASIL, Parecer do CNE/CES 492/2001 do Ministério da Educação. Disponível em: http://portal.mec.gov.br/cne/arquivos/pdf/CES0492.pdf. Acesso em: 02 de junho de 2017.

BRONCKART, J-P. Por que e como analisar o trabalho do professor. IN: MACHADO, A.R. MATÊNCIO, M.L.M. (Orgs). Atividade de linguagem, discurso e desenvolvimento humano. Campinas, SP: Mercado de Letras, 2006a, p. 203-229.

Ana Patrícia

Sá Martin
Ação, discurso e racionalização: a hipótese de desenvolvimento de Vygotsky revisitada. IN: MACHADO, A.R.; MATÊNCIO, M.L.M. (Orgs). Atividade de linguagem, discurso e desenvolvimento humano. Campinas, SP: Mercado de Letras, 2006b, p. 59-92.

Os gêneros de textos e os tipos de discurso como interações propiciadoras de desenvolvimento. IN: MACHADO, A.R.; MATÊNCIO, M.L.M. (Orgs). Atividade de linguagem, discurso e desenvolvimento humano. Campinas, SP: Mercado de Letras, 2006c, p. 121-160.

BRONCKART, J-P.; MACHADO, A.R. Procedimentos de análise de textos sobre o trabalho educacional. In: MACHADO,A.R. (org) 0 ensino como trabalho. Londrina:EDUEL, 2004. p.131-163.

. Um retorno necessário à questão do desenvolvimento. IN: BUENO, L.; LOPES, M.A.P.T.; CRISTÓVÃO, V.L.L. (Orgs). Gêneros textuais e formação inicial: uma homenagem à Malu Matêncio. Campinas, SP: Mercado de Letras, 2013, p. 85 -107.

BULEA, E. Linguagem e efeitos desenvolvimentais da interpretação da atividade. Campinas: Mercado de Letras, 2010.

BULEA-BRONCKART, E.; LEURQUIN, E.V.L.F.; CARNEIRO, F. D. V.O agir do professor e as figuras de ação: por uma análise interacionista. IN: BUENO, L.; LOPES, M.A.P.T.; CRISTÓVÃO, V.L.L. (Orgs). Gêneros textuais e formação inicial: uma homenagem à Malu Matêncio. Campinas, SP: Mercado de Letras, 2013, p. 109-132. 
CARNIN, A. Na escrita do professor, um percurso possível para a análise do (seu) desenvolvimento profissional. São Leopoldo, RS. Tese de Doutorado em Linguística Aplicada. Universidade do Vale do Rio dos Sinos - UNISINOS, 2015.

CARNIN, A.; GUIMARÃES, A.M.M. Agir linguageiro, tomada de consciência e desenvolvimento profissional do professor em formação continuada. RBLA, Belo Horizonte, v. 16, n. 3, p. 365-385, 2016. Disponível em: http://www.scielo.br/pdf/rbla/v16n3/1984-6398rbla-16-03-00365.pdf. Acesso em: 20 de fevereiro de 2017.

COSCARELLI, Carla Viana. Tecnologias para aprender. São Paulo: Parábola, 2016.

Reflexões do agir docente sobre o uso das tecnologias nas práticas de leitura e escrita na formação do futuro professor de língua portuguesa

CRISTOVÃO, V. L. Gêneros textuais e educação inicial do professor de língua inglesa. Linguagem em (Dis)curso, Palhoça, SC, v. 10, n. 3, p. 705-734, set./dez. 2010. Disponível em: http://www.scielo.br/ pdf/ld/v10n3/13.pdf Acesso em 10 de janeiro de 2016.

DIONISIO, A. P. Multimodalidade discursiva na atividade oral e escrita (atividades). In: MARCUSCHI, L. A.; DIONISIO, A. P. (Orgs.). Fala e escrita. Belo Horizonte: Autêntica, 2005.

DREY, R.F. O processo inicial de competência profissional docente : por uma análise multimodal do trabalho real. São Leopoldo, RS. Tese de Doutorado. Universidade do Vale do Rio dos Sinos - UNISINOS, 2011.

GOROSPE, J. M. C. et al. Formación del Profesorado, Tecnología Educativa e Identidad Docente Digital. RELATEC Revista Latinoamericana de Tecnología Educativa. vol 14(1), 2015. Disponível em: https://www. researchgate.net/publication/ Acesso em 04 de abril de 2017.

KERSCH, D. F.; MARQUES, R. G. Projetos didáticos de Gênero, multimodalidade, uso de tecnologias e participação em comunidade de prática: uma experiência na formação de 15 professores. In: $\mathrm{KERSCH}$, D. F.; CANI, J.; COSCARELLI, C.V. Multiletramentos e multimodalidade: ações pedagógicas aplicadas à linguagem São Paulo: Pontes, 2016. 
KLEIMAN, A.B. Letramento na contemporaneidade. Bakhtiniana, São Paulo, 9 (2): 72-91, Ago./Dez. 2014.

MACHADO, A.R.; BRONCKART, J-P. (Re) configurações do trabalho do professor construídas nos e pelos textos: a perspectiva metodológica do Grupo ALTER-LAEL. In: MACHADO, A. R.; ABREU-TARDELLI, L. \& CRISTOVÃO, V. L. L. (Orgs.). Linguagem e educação: o trabalho do professor em uma nova perspectiva. Campinas, SP: Mercado de Letras, 2009. p. 31-77.

Ana Patrícia

Sá Martin

MACHADO,A.R.et al. Breve definição dos fundamentos e procedimentos dos estudos do trabalho do professor. In: 0 professor e seu trabalho: a linguagem revelando práticas docentes. Campinas:Mercado de Letras, 2011,p. 15-28

OAKLEY, G. et al. Apresentação de e-portfólios para o pré-serviço de professores como ferramentas para Reflexão e crescimento: lições aprendidas. Asia-Pacific Journal of Teacher Education, 2013. Disponível em: http://dx.doi.org/10.1080/1359866X.2013.854860. Acesso em 04 de abril de 2017.

PEGRUM, M. et al. Letramentos digitais. São Paulo: Parábola, 2016.

STREET, B. Eventos de letramento e práticas de letramento: teoria e prática nos novos estudos de letramento. In. MAGALHÃES, I. (org.) Discursos e práticas de letramento. Campinas, Mercado de Letras, 2012.

. Letramentos sociais: abordagens críticas do letramento no desenvolvimento, na etnografia e na educação. Traduzido por Marcos Bagno. São Paulo: Parábola, 2014. 